\title{
MJN EXPLORING NURSES' KNOWLEDGE OF THE GLASGOW COMA SCALE IN INTENSIVE CARE AND EMERGENCY DEPARTMENTS AT A TERTIARY HOSPITAL IN RIYADH CITY, SAUDI ARABIA
}

\author{
Abdulrhman Albougami \\ Department of Nursing, College of Applied Medical Sciences, Majmaah University, Saudi Arabia \\ Corresponding Author's Email: a.albougami@mu.edu.sa
}

\begin{abstract}
Purpose: The present study determines the factors affecting knowledge of the Glasgow Coma Scale (GCS) of emergency room (ER) and intensive care unit (ICU) nurses who work at a tertiary hospital in Riyadh, Saudi Arabia. Methods: A cross-sectional study with self-administered questionnaire was conducted among 149 ICU and ER nurses conveniently selected at a tertiary hospital in Saudi Arabia. A standardized tool was used to assess knowledge of the GCS. The study adhered to the STROBE guideline for cross-sectional studies. Results: Expatriate nurses $(p<0.001)$ and those with a postgraduate degree $(p<0.05)$ were found to have more knowledge of the GCS. Nurses with expertise in ICU services scored significantly higher $(p<0.001)$ than those who work in the ER. Nurses reporting no previous training in the GCS had higher scores $(p<0.05)$ than those who had previous training in the GCS. Conclusion: Some of the demographic characteristics and nurses' knowledge about the GCS were associated. Expatriate, postgraduate, and ICU nurses were more knowledgeable about the GCS tool. Surprisingly, nurses without GCS additional training had more GCS knowledge than nurses who had attended training. The results provide valuable insights into and guidance for improving GCS knowledge among ICU and ER nurses.
\end{abstract}

Keywords: Critical Care, Comatose, Emergency Department, Glasgow Coma Scale

\section{INTRODUCTION}

Healthcare professionals (HCPs) are anticipated to be imbued with related theoretical and practice experience to deliver quality patient care, which involves complete and continuous patient assessment (Al-Quraan \& AbuRuz, 2016). Nurses' continuous assessments often involve neurological patients, specifically, the level of consciousness, which is considered the central assessment criterion (Al-Quraan \& AbuRuz, 2016). There are numerous tools for assessing patients' neurological status (Basauhra Singh et al., 2016). One universally accepted tool is the Glasgow Coma Scale (GCS). HCPs, especially nurses, use the GCS in assessing patients' level of consciousness (Mattar, Liaw \& Chan, 2013).

The GCS is a scoring system that assesses patients' level of consciousness in response to a certain stimulus (Mattar, Liaw \& Chan, 2013). The tool is a reliable clinical technique for assessing the severity of a neurological injury (Mattar, Liaw \& Chan, 2015). The GCS measures three detailed neurological functions: eye-opening, verbal responsiveness, and motor responsiveness (which conclude inappropriate initial signs of neurological deterioration) (Mattar, Liaw \& Chan, 2013). This scale can help HCPs who work in emergency and intensive care units in particular to swiftly execute proper diagnostic measures and to initiate proper nursing interventions for patients (Mattar, Liaw \& Chan, 2013). Nurses play an active and central role in healthcare settings. A nurse is routinely the first person with whom a patient interacts (Cruz et al., 2018). Nurses are responsible for nursing assessment and preparing proper nursing interventions. Thus, nurses should be competently knowledgeable to assess neurological changes and be prepared with the clinical skills necessary to provide quality patient care (Mattar, Liaw \& Chan, 2015).

Nurses from different countries and regions vary 
considerably in their knowledge of the GCS. For example, nurses in South America (Ehwarieme \& Anarado, 2016; Santos et al., 2016) have been observed to be somewhat knowledgeable in demonstrating the GCS in clinical settings. Brazilian nurses in emergency and intensive care units had high knowledge of the GCS (Santos et al., 2016). However, concerns have been raised regarding the lack of precision and inconsistency when the GCS is used. Malaysian nurses were found to have poor knowledge of the GCS, only $2.96 \%$ of nurses were knowledgeable about the GCS (Basauhra Singh et al., 2016).

Similarly, nurses in the Middle East face the same challenges in their knowledge of erformance of the GCS. Jadduoa, Mohammed \& Abbas (2013) found that Iranian nurses have difficulty handling patients with consciousness problems and evaluating patients' overall neurological status. A descriptive study by Eldesouky (2016) discussed why Egyptian nurses have low GCS knowledge and stated that they have less exposure in educational programs and training to the GCS. This finding implies nurses might have lower cognitive skills and experience in using the GCS

In Saudi Arabia, similar to other Middle Eastern countries, patients' level of consciousness is assessed with the GCS. Surprisingly, in one previous study in Saudi Arabia have reportedly no preparations and strategies for any neurologic assessment tool (Hassan, 2017). Similarly, most nurses score the GCS based on their own understanding (Jadduoa, Mohammed \& Abbas, 2013). This individual understanding might lead nurses who seldom use the scale to erroneous assessments of neurological changes and monitoring and recording of neurological observations in patients. Assessment errors are potentially dangerous for patient health in performing GCS procedure. Nurses must be competent in using the GCS to guarantee accurate interpretations when they assess patients (Basauhra Singh et al., 2016).

However, several studies have revealed that nurses lack adequate knowledge regarding use of this scale, indicating a need to better quantify and standardize the GCS within nursing education and continuing training programs. Although extensive research pertaining to strategies for encouraging nurses to use the GCS and improving nurses' knowledge of the GCS have been conducted (Mattar, Liaw \& Chan, 2013). It is unclear whether the strategies are useful for conducting neurological patient assessments in a country in which nurses come from many different countries (e.g., Saudi Arabia, the Philippines, India, Egypt, and the Sudan) (Almutairi \& McCarthy, 2012) and have different educational programs. Similarly, little is known about how cultural differences might influence nurses' knowledge of the GCS and enable nurses to fulfill their multiple clinical roles. Empirical data also showed that nurses are inconsistent and inaccurate when they perform the GCS in a mentoring system, which is a critical component of assessment and care of patients experiencing trauma, surgery, and neurological effects (Santos et al., 2016). Keeping patients safe is a dimension of high-quality healthcare, and nurses are the key to ensuring that patients receive the best possible care (Ehwarieme \& Anarado, 2016). Therefore, it is important to assess nurses' knowledge. This study aimed to determine the knowledge level of the GCS among emergency and critical care nurses in Saudi Arabia. The study makes a significant contribution to nursing programs and hospitals by providing a comprehensive basis for improving the Saudi curriculum and developing educational and training materials for nurses.

\section{Aim of study}

The present study examined the factors that affect knowledge of the GCS of emergency room (ER) or intensive care unit (ICU) nurses who work at a tertiary hospital in Riyadh, Saudi Arabia.

\section{METHODOLOGY}

\section{Research design}

The study utilized a cross-sectional design with convenient sampling. This was to quantify the information pertaining to knowledge of GCS of nurses (ER and ICU) at a specific point in time.

\section{Setting and sample}

This study was conducted in a public hospital (bed capacity $=1500$ ) in Saudi Arabia. The hospital is a tertiary-care teaching multi-facility and multidisciplinary medical center for Saudi and non-Saudi citizens.

The inclusion criteria were follows: (a) registered nurses, (b) assigned to the ER or ICU for more than 6 months, (c) male or female, (d) Saudi or non-Saudi, (e) proficient in English. The exclusion criteria included the following: unit managers and clinical resource nurses, and nurse educators. 
A total of 196 staff nurses from the hospital met the inclusion criteria, and they were recruited to participate. Only 157 respondents consented to answer the survey. Overall, after the data were collected, a total of 149 ICU and ER nurses were included in the data analysis (response rate $=76.02 \%$ ).

\section{Data collection}

Convenience sampling involved ER and ICU nurses from October to December 2018. First, researchers made a courtesy call to the nursing director with a written request to conduct the study. The study purpose was clearly explained to the nursing director and chief nurse, so that their cooperation could be solicited. Then, the questionnaires were distributed to the respondents with the assistance of the nurse supervisor in each area. The study purpose and the right to withdraw from the study at any time were discussed with each respondent. The questionnaire was distributed in their breaks during work shift. The questionnaires were designed and printed in an optical mark sheet form. The participants marked their answers using a pencil, which was provided with the questionnaires distributed at one time. After 2 weeks, the researchers collected the questionnaires. The data files were coded, backed up, and password protected. The completed consent forms and questionnaires were stored in a locked cabinet.

\section{Instruments}

The study used a two-part self-administered questionnaire during data collection.

Demographic data collection: The first part asked about the nurses' demographic characteristics, including gender, age, nationality, level of education, clinical discipline, length of time in current discipline, and course or training related to the GCS.

Knowledge level of the GCS: The second part of the questionnaire consisted of 15 multiple-choice questions, assessed ER and ICU nurses' knowledge of the GCS in the following areas: definition, indication, components, and GCS scores (Mattar, Liaw \& Chan, 2013). The nurses' scores ranged from 0 to 15 . Items 6 and 12 were true/false statements. A higher score means more knowledge of the GCS. The 15-item standardized questionnaire had satisfactory reliability $(\mathrm{a}=0.71)$ (Mattar, Liaw \& Chan, 2015).
The questionnaire was pilot tested at another hospital which have the same characteristic and underwent expert validation (6 nurses) in the field of nursing research (2 nurse educators) and emergency nursing (2 staff nurses) and intensive care nursing (2 staff nurses). The purpose was to determine the appropriateness of the survey. Four experienced nurses (e.g., emergency nursing and intensive care nurses) performed the expert validation to clarify whether the survey was realistic and feasible for the respondents.

\section{Statistical analysis}

The statistical analysis was performed with SPSS version 23.0. Descriptive details of the participant characteristics are presented using the mean and standard deviation and frequency with a percentage. The distributions of the correct responses are described using frequency in percentage. Relationship between participants' characteristics and knowledge of the GCS were assessed using the Kruskal-Wallis test, the MannWhitney test, and an independent $t$-test.

\section{Ethical considerations}

Ethical approval to collect the data was obtained from the Ministry of Health (18-367E). The study's purpose and procedures were explained in a cover letter. A signed consent form was obtained from respondents who agree to participate. Respondents had the right to refuse to participate and to withdraw from the study at any time. Numerical codes replaced the respondents' names on the questionnaires to ensure confidentiality. No benefits were accrued to the participants, although the outcomes of the study will provide recommendations for future nursing education and practice in Saudi Arabia.

\section{RESULTS}

\section{Participants' characteristics}

The majority of the participating nurses (59.1\%) were female, and most (60.4\%) were young adults aged between 20 to 30 years. More than half of the participants, that is, 57\%, were expatriates. Most (79.2\%) reported a bachelor's degree as their highest level of education. About two thirds of the participants $(78.5 \%)$ had 1 year or more of clinical experience. The majority of the nurses $(69.1 \%)$ did not have previous training in the GCS (See Table 1). 
Table 1: Nurses characteristics and Socio-demographic predictors of Knowledge on Glasgow Coma Scale working in hospital, Saudi Arabia

\begin{tabular}{|c|c|c|c|c|}
\hline Characteristics & number(percentage) & $\begin{array}{l}\text { Mean } \pm \text { SD } \\
\text { Total score of the } \\
\text { questionnaire }\end{array}$ & $X^{2} / Z /$ t-statistics & $P$-value \\
\hline $\begin{array}{l}\text { Gender } \\
\\
\text { Male } \\
\text { Female }\end{array}$ & $\begin{array}{l}61(40.9) \\
88(59.1)\end{array}$ & $\begin{array}{l}7.74 \pm 1.81 \\
7.41 \pm 2.26\end{array}$ & $-0.981^{\mathrm{c}}$ & 0.328 \\
\hline $\begin{array}{r}\text { Age (In years) } \\
20-30 \\
31-40 \\
41-50\end{array}$ & $\begin{array}{c}90(60.4) \\
51(34.2) \\
8(5.4)\end{array}$ & $\begin{array}{l}7.70 \pm 2.23 \\
7.45 \pm 1.87 \\
6.38 \pm 1.50\end{array}$ & $X^{2}(d f=2)=5.00^{\mathrm{a}}$ & 0.082 \\
\hline $\begin{array}{l}\text { Nationality } \\
\text { Saudi } \\
\text { Expatriates }\end{array}$ & $\begin{array}{l}64(43.0) \\
85(57.0) \\
\end{array}$ & $\begin{array}{l}6.59 \pm 2.23 \\
8.26 \pm 1.66\end{array}$ & $-5.014^{\mathrm{c}}$ & 0.000 \\
\hline $\begin{array}{c}\text { Highest qualification } \\
\text { Diploma } \\
\text { Bachelors } \\
\text { Post graduate } \\
\end{array}$ & $\begin{array}{c}19(12.8) \\
118(79.2) \\
12(8.1) \\
\end{array}$ & $\begin{array}{l}6.21 \pm 2.76 \\
7.69 \pm 1.88 \\
8.17 \pm 2.21 \\
\end{array}$ & $X^{2}(d f=2)=6.226^{\mathrm{a}}$ & 0.044 \\
\hline $\begin{array}{c}\text { Area of expertise } \\
\text { ER } \\
\text { ICU }\end{array}$ & $\begin{array}{l}78(52.3) \\
71(47.7)\end{array}$ & $\begin{array}{l}6.91 \pm 1.89 \\
8.24 \pm 2.10\end{array}$ & $-4.055^{\mathrm{c}}$ & 0.000 \\
\hline $\begin{array}{l}\text { Experience in years } \\
\text { Less than } 1 \\
1-3 \\
4-6 \\
\text { More than } 7\end{array}$ & $\begin{array}{l}32(21.5) \\
55(36.9) \\
40(26.8) \\
22(14.8)\end{array}$ & $\begin{array}{l}6.94 \pm 2.03 \\
7.47 \pm 2.19 \\
7.92 \pm 1.89 \\
7.91 \pm 2.18\end{array}$ & $X^{2}(d f=2)=6.147^{\mathrm{a}}$ & 0.105 \\
\hline $\begin{array}{l}\text { Additional Training for } \\
\text { GCS } \\
\qquad \begin{array}{c}\text { Yes } \\
\text { No }\end{array}\end{array}$ & $\begin{array}{c}46(30.9) \\
103(69.1)\end{array}$ & $\begin{array}{l}6.96 \pm 2.25 \\
7.80 \pm 1.97\end{array}$ & $Z=-2.788^{b}$ & 0.005 \\
\hline
\end{tabular}

${ }^{a}$ Kruskal Wallis test, ${ }^{b}$ Mann-Whitney test, ${ }^{c}$ Independent t-test

GCS: Glasgow Coma Scale, ER: Emergency room; ICU: Intensive care unit

\section{Sociodemographic predictors of knowledge of the GCS}

Expatriate nurses $(8.26 \pm 1.66)$ scored higher than Saudi nurses $(6.59 \pm 2.23)$ on knowledge of the GCS, $t$ $=5.014, p<0.001$. Those with a postgraduate degree scored the highest $(8.17 \pm 2.21)$, followed by those with a bachelor's degree (7.69 \pm 1.88$)$, and those with a diploma in nursing $(6.21 \pm 2.76)$ scored the lowest, $\mathrm{X}^{2}(2)=6.226, p=0.044$. Nurses with expertise in ICU $(8.24 \pm 2.10)$ services scored statistically significantly higher than those who working in the ER (6.91 \pm 1.89$), t$ $=-4.055, p<0.00$. Surprisingly, nurses who reported no previous training in the GCS scored higher $(7.80 \pm 1.97)$ than those who had previous training in the GCS
(6.96 \pm 2.25$), Z=-2.788, p=0.005$ (See Table 1).

\section{Pattern of responses for the instrument for assessing knowledge of the GCS}

The four questions that were answered correctly by more than three fourths of the nurses were about the purpose of the GCS $(87.9 \%)$, the lowest score on the GCS (79.2\%), specific sections of the GCS (78.5\%), and no applicability of the GCS in assessing the level of consciousness in intubated patients $(78.5 \%)$. The questions that received the highest number of incorrect answers were about assessment of the confused state of a patient $(4.0 \%)$, which arm to use while assessing motor function $(12.1 \%)$, and the neuroanatomy of eye opening $(20.1 \%)$ (See Table 2$)$. 


\begin{tabular}{|c|c|}
\hline $\begin{array}{l}\text { Items of the Instrument to Assess Knowledge on } \\
\text { Glasgow Coma Scale }\end{array}$ & $\begin{array}{l}\text { Frequency } \\
\text { (percentage) } \\
\text { of correct } \\
\text { responses }\end{array}$ \\
\hline 1. The Glasgow Coma Scale was initially devised to & $131(87.9)$ \\
\hline $\begin{array}{l}\text { 2. What part of the brain is being assessed when you are } \\
\text { assessing eye opening? }\end{array}$ & $30(20.1)$ \\
\hline $\begin{array}{l}\text { 3. Which part of the brain is being assessed when you are } \\
\text { assessing verbal response? }\end{array}$ & $58(38.1)$ \\
\hline $\begin{array}{l}\text { 4. Which part of the brain is being assessed when you are } \\
\text { assessing motor response? }\end{array}$ & $70(47.0)$ \\
\hline $\begin{array}{l}\text { 5. What are the specific sections that comprise the } \\
\text { Glasgow Coma Scale? }\end{array}$ & $117(78.5)$ \\
\hline $\begin{array}{l}\text { 6. Vital signs are a component of the Glasgow Coma } \\
\text { Scale. }\end{array}$ & $81(54.4)$ \\
\hline 7. When testing the best motor response, you & $18(12.1)$ \\
\hline $\begin{array}{l}\text { 8. To test motor response in tetraplegia patients (paralyzed } \\
\text { in all four limbs) }\end{array}$ & $91(61.1)$ \\
\hline 9. The lowest score of the Glasgow Coma Scale is & $118(79.2)$ \\
\hline $\begin{array}{l}\text { 10. Patients with a Glasgow Coma Scale score of-and } \\
\text { below are considered comatose. }\end{array}$ & $69(46.3)$ \\
\hline $\begin{array}{l}\text { 11. In nursing practice, a reduction of the Glasgow Coma } \\
\text { Scale score of-is seen as deterioration in conscious } \\
\text { level and requires informing the medical team. }\end{array}$ & $65(43.6)$ \\
\hline $\begin{array}{l}\text { 12. The Glasgow Coma Scale cannot assess intubated } \\
\text { patient's level of consciousness. }\end{array}$ & $117(78.5)$ \\
\hline $\begin{array}{l}\text { 13. on asking a patient, "Do you know where you are } \\
\text { now?" the patient states he is at his daughter's } \\
\text { condominium. He is }\end{array}$ & $6(4.0)$ \\
\hline $\begin{array}{l}\text { 14. On assessing a patient's motor response, he is unable to } \\
\text { comply. You inflict a pain stimulus, and he pulls his } \\
\text { arm away. He }\end{array}$ & $84(56.4)$ \\
\hline $\begin{array}{l}\text { 15. You are assessing an RTA (road traffic accident) } \\
\text { patient, who has swollen eyes. You instruct him to open } \\
\text { his eyes, but he is unable to. The eye response score is }\end{array}$ & $69(46.3)$ \\
\hline
\end{tabular}

\section{DISCUSSION}

This study set out to determine the factors that affect the knowledge of the GCS of ER and ICU nurses who work at a public hospital setting in Riyadh, Saudi Arabia. Five main findings are discussed.

First, in terms of demographic and work-related factors, expatriate nurses were more knowledgeable than Saudi nurses. This is worth noting because nursing care is considered a less-than-acceptable career choice for the majority of Saudi nationals (Al-Mahmoud, Mullen \& Spurgeon, 2012). Additionally, the continued low image of the nursing profession, and low desirability may contribute to the lack of interest in learning nursing concepts, particularly the GCS. A previous study reported Saudi nurses have difficulty organizing patient care in a systematic and holistic way (Al-Mahmoud, Mullen \& Spurgeon, 2012). According to Mutair (2015), Saudi graduates are employed immediately after graduation. A dearth of clinical experience might explain why new Saudi nurses feel puzzled about their role (Mutair, 2015).
Given these factors, delivering patient care remains a very serious issue and a challenge for nursing staff. However, to become staff nurses in Saudi Arabia, expatriates must fulfill many requirements (Alosaimi \& Ahmad, 2016). Specifically, the requirements are clinical years of experience with rigorous credential evaluations and a passing score on the Saudi Commission Nursing Board examinations for health specialties. As a result, expatriate nurses might have greater orientation in GCS responsible nursing practice. Therefore, expatriate nurses' knowledge of nursing care and patient GCS assessment may be influenced. To improve Saudi nurses' nursing care performance, an effort to recognize and increase knowledge of the GCS is necessary.

Second, nurses' level of education influenced their knowledge of the GCS. In this study, nurses with postgraduate degrees had better knowledge of the GCS compared to nurses with a diploma and nurses with a bachelor's degree. This finding was also reported by Basauhra Singh et al., (2016), who found that educational attainment influences GCS understanding among 135 Malaysian ER nurses and outpatient department (OPD) nurses. Similar results were also found in a study among nurses in Singapore (Mattar, Liaw \& Chan, 2013) and in a study in Brazil (Santos et al., 2016). According to AlQuraan \& AbuRuz (2016), higher educational attainment means increased GCS knowledge which could positively affect a nurse's neurological assessment. Thus, the higher the educational attainment, the more likely better knowledge attainment of GCS.

Conversely, the present study results do not confirm previous studies and showed no statistically significant association between educational attainment and knowledge of the GCS (Al-Quraan \& AbuRuz, 2016; Jadduoa, Mohammed \& Abbas, 2013). According to Matthias (2015), nurses with postgraduate degrees are not shown to be more accurate in assessment compared with registered nurses who possess either a diploma or a bachelor's degree. This research gap regarding the complexity of nurses' educational attainment warrants further exploration.

Third, a nurse's area of expertise affects GCS knowledge. In this study, ICU nurses had more GCS knowledge than ER nurses. This result may be because the ICU is a highly specialized healthcare unit in which the majority of the high-risk patients have a neurological condition; this setting might require a tool for quick assessment of the changes and performing a nursing intervention (Keykha et al., 2017). In previous literature, 
patient neurological assessment has been described as an indispensable tool in ICU daily practice compared to other nursing departments (Jadduoa, Mohammed \& Abbas, 2013). According to Keykha et al., (2017), the ICU is a specialized unit in which assessment of the level of consciousness is continuously implemented by nurses. Santos et al., (2016) found that ICU nurses must conduct the GCS hourly irrespective of case type. It is highly likely that the more nurses conduct the GCS, the greater their confidence in using the scale. This finding confirms Mattar, Liaw \& Chan's (2013) finding that ICU nurses' are constantly exposed to patients with neurological disorder. As a result ICU nurses made more accurate GCS assessments and fewer assessment errors (Al-Quraan \& AbuRuz, 2016). In addition, Al-Quraan \& AbuRuz (2016) reported that the ICU has an annual competency evaluation that included a concise meeting about assessing the level of consciousness among Jordanian nurses. This frequent evaluation encounter with the neurological assessment made the nurses familiar with the GCS. Overall, it is important for nurses to be competent in monitoring neurological observations and equipped with the clinical skills require.

Fourth, professional development opportunities, such as training and workshops, appear to be important for upgrading knowledge and skills in professional practice and providing quality patient care. Surprisingly, in this study, nurses without additional training had better GCS knowledge compared to those who had additional training. A possible reason is that all respondents were ICU nurses and ER nurses which critically affect their neurological assessment performance. For example, in the ER, nurses used the GCS to triage patients with impaired consciousness and to improve communication between providers (Basauhra Singh et al., 2016). In the ICU, the GCS is a standard scale which is crucial for nurses' assessment of patients' level of consciousness (Mattar, Liaw \& Chan, 2013). In these types of working conditions, it is most likely that nurses consistently practice neurological examinations.

In contrast, Ehwarieme \& Anarado (2016) suggested that reinforcement of GCS information facilitates GCS learning among nurses. This suggestion is also in harmony with a previous study (Santos et al., 2016), which elaborated that nurses who attended a GCS training workshop had greater understanding of the GCS compared with nurses who had not undertaken such training (Al-Quraan \& AbuRuz, 2016). The study also reported that training increased GCS knowledge, and improved nurses' work performance (Al-Quraan \&
AbuRuz, 2016). In Shehab, Ibrahim \& Abd-Elkader's analysis (2018), a correct GCS assessment is unachievable without experienced, competent, welltrained nurses, especially in the ICU and the emergency department. It is almost certain that nurses could have effective assessment skills to cope with patient problems, particularly with fluctuating levels of consciousness. To provide a quality nursing care assessment, GCS knowledge should be continuously updated with protocols that direct the assessment of nurses' performance of the GCS. Thus, to achieve a knowledgeable nurse, a training education program and constant evaluation of a nurse's performance can aid in appropriate assessment and management of patient care.

Finally, most nurses understood that the GCS was devised to assess the depth of coma. This result negates the finding of a previous study that due to the difficulty of the GCS assessment and the way it is defined, nurses reported that the GCS is difficult to use for the assessment of patients in a coma (Ehwarieme \& Anarado, 2016). A previous survey reported when tested on the GCS, even neurosurgeons get it right only $56 \%$ of the time. Military doctors calculate the GCS correctly only $15 \%$ of the time (Scancrit, 2011). However, this previous literature should be interpreted with caution because the study respondents were physicians, and not nurses, which could affect the findings of the study. Another study reported that assessing comatose patients is complex because of the inconvenience of catching distinctive features during clinical assessment (Mattar, Liaw \& Chan, 2013). The assessment complexity can also be enlightened by the struggle of ruling out practical terminology to explain the patient's deep comatose status (Ahmed, 2015). It is most likely that comatose patients are hard to assess. Thus, continuous orientation and training activities for the GCS should be implemented to improve nurses' knowledge of skills in adherence to neurological quality standards.

\section{Limitations}

Several limitations should be acknowledged. First, nurses were recruited from the ICU and the ER at one public tertiary hospital which might limit the generalizability results. A self-reported questionnaire was used in which respondents might not have reported answers or chose a favorable response to avoid disapproval. Consequently, the survey might not adequately present nurses' true GCS assessment skill level. A convenience sample was used which limits the generalization to nurses working in Saudi Arabia. Nurses 
have different cultural backgrounds, and thus, might have different training perceptions and implementations of the GCS which makes it difficult to compare GCS knowledge.

Despite these limitations, a major strength of the study was that it was performed in a tertiary health facility where the highest volume of clients is expected, and professional experts are trained and offer services. Thus, the best experts in knowledge should be found. Finally, the findings elucidate the importance of systematic education in the GCS, including practical training for Saudi nurses working here.

\section{CONCLUSION}

The present study contributes to the understanding of factors that affect the GCS knowledge of ICU and ER nurses who work in a public hospital setting in Riyadh, Saudi Arabia. Demographic characteristics were associated with nurses' knowledge of the GCS.
Specifically, expatriate nurses, nurses with postgraduate degrees, and ICU nurses were more knowledgeable about the GCS. Surprisingly, nurses without additional GCS training had more GCS knowledge than nurses with training. The results provide valuable insights into and guidance for improving knowledge of the GCS among ICU and ER nurses.

The study results provide valuable information for articulating approaches to inspire nurses to use the GCS, especially Saudi nurses and those who hold bachelor's degree to improve their knowledge of the GCS and determine actual GCS problems ensuing mentoring or training. Nursing administrators could provide educational involvement and strategies for GCS performance to all nurses who care for unconscious patients. Manual procedure could be distributed by Nursing Instructors to the nurses working in the ICU and the emergency department that includes the standards for the GCS technique.

\section{REFERENCES}

Ahmed, I.M. (2015). Comparison between neurological assessment of inexperienced and experienced intensive care nurses using GCS and FOUR. Journal of American Science, 11(1s), pp 1-7.

Al-Mahmoud, S., Mullen, P. \& Spurgeon, P. (2012). Saudisation of the nursing workforce: Reality and myths about planning nurse training in Saudi Arabia. Journal of American Science, 8(4), pp 369-379.

Almutairi, A. \& McCarthy, A.L. (2012). A multicultural nursing workforce and cultural perspectives in Saudi Arabia: An overview. The Health, 3(3), pp 71-74.

Alosaimi, D.N. \& Ahmad, M.M. (2016). The challenges of cultural competency among expatriate nurses working in Kingdom of Saudi Arabia. Research and Theory for Nursing Practice, 30(4), pp 302-319.

Al-Quraan, H. \& AbuRuz, M.E. (2016). Assessment of Jordanian nurses' knowledge to perform Glasgow Coma Scale. European Scientific Journal, 12(27), pp 208-217.

Basauhra Singh, H.K., Chong, M.C., Thambinayagam, H.C., Zakaria, M.I., Cheng, S.T., Tang, L.Y. \& Azahar, N.H. (2016). Assessing nurse's knowledge of Glasgow Coma Scale in emergency and outpatient department. Nursing Research and Practice, 2016, pp 1-5.

Cruz, J.P., Cabrera, D.N.C., Hufana, O.D., Alquwez, N. \& Almazan, J. (2018). Optimism, proactive coping and quality of life among nurses: A cross-sectional study. Journal of Clinical Nursing, 27(9-10), pp 2098-2108.

Ehwarieme, T.A. \& Anarado, A.N. (2016). Nurses' knowledge of Glasgow Coma Scale in neurological assessment of patients in a selected tertiary hospital in Edo State, Nigeria. Africa Journal of Nursing and Midwifery, 18(2), pp 74-86.

Eldesouky, E.I. (2016). Impact of an educational program for nurses' knowledge and practice about Glasgow Coma Scale. International Journal of Recent Scientific Research, 7(3), pp 9690-9695.

Hassan, M.M. (2017). Strategies of improving the nursing practice in Saudi Arabia. Journal of Health Education Research \& Development, 5(2), 1000221.

Jaddoua, B.A., Mohammed, W.K. \& Abbas, A.D. (2013). Assessment of nurse's knowledge concerning Glasgow Coma 
Scale in neuro surgical wards. Kufa Journal for Nursing Sciences, 3(2), pp 133-142.

Keykha, A., Askari, H., Navidian, A. \& Hosseini, B.M.K. (2017). Ability of Glasgow Coma Scale and full outline of unresponsiveness score in measuring level of consciousness and outcome in patients receiving sedation under mechanical ventilation. Journal of Critical Care Nursing, 10(1), pp 1-6.

Mattar, I., Liaw, S.Y. \& Chan, M.F. (2013). A study to explore nurses' knowledge in using the Glasgow Coma Scale in an acute care hospital. Journal of Neuroscience Nursing, 45(5), pp 272-280.

Mattar, I., Liaw, S.Y. \& Chan, M.F. (2015). Nurses' self-confidence and attitudes in using the Glasgow Coma Scale: A primary study. Nursing in Critical Care, 20(2), pp 98-107.

Matthias, A.D. (2015). Making the case for differentiation of registered nurse practice: Historical perspectives meet contemporary efforts. Journal of Nursing Education and Practice, 5(4), pp 108-114.

Mutair, A.A. (2015). Quality of nursing care in Saudi Arabia: Needs for improvement. Journal of Nursing Care, 4(6), 1000309.

Santos, W.C., Vancini-Campanharo, C.R., Lopes, M.C.B.T., Okuno, M.F.P. \& Batista, R.E.A. (2016). Assessment of nurse's knowledge about Glasgow Coma Scale at a university hospital. Einstein, 14(2), pp 213-218.

Scancrit (2011). Why the Glasgow Coma Scale has got to go. Retrieved from: http://www.scancrit.com/2011/11/ 28/why-the-glasgow-coma-scale-has-got-to-go/

Shehab, M.S., Ibrahim, N.M. \& Abd-Elkader, H. (2018). Impact of an educational program on nurses' knowledge and practice regarding care of traumatic brain injury patients at intensive care unit at Suez Canal University Hospital. International Journal of Caring Sciences, 11(2), pp 1104-1116. 